\title{
Role of Long-Range Dispersion Forces in Modeling of MXenes as Battery Electrode Materials
}

Tygesen, Alexander S.; Pandey, Mohnish; Vegge, Tejs; Thygesen, Kristian Sommer; García-Lastra, Juan .

Published in:

The Journal of Physical Chemistry Part C

Link to article, DOI:

10.1021/acs.jpcc.8b11663

Publication date:

2019

Document Version

Peer reviewed version

Link back to DTU Orbit

Citation (APA):

Tygesen, A. S., Pandey, M., Vegge, T., Thygesen, K. S., \& García-Lastra, J. M. (2019). Role of Long-Range Dispersion Forces in Modeling of MXenes as Battery Electrode Materials. The Journal of Physical Chemistry Part C, 123(7), 4064-4071. https://doi.org/10.1021/acs.jpcc.8b11663

\section{General rights}

Copyright and moral rights for the publications made accessible in the public portal are retained by the authors and/or other copyright owners and it is a condition of accessing publications that users recognise and abide by the legal requirements associated with these rights.

- Users may download and print one copy of any publication from the public portal for the purpose of private study or research.

- You may not further distribute the material or use it for any profit-making activity or commercial gain

- You may freely distribute the URL identifying the publication in the public portal 


\section{Effect of Long-Range Dispersion DFT}

\section{Functionals in Modelling Li-ion Transport in Layered MXenes}

Alexander S. Tygesen, ${ }^{\dagger}$ Juan M. García-Lastra, ${ }^{*}, \dagger$ Tejs Vegge, ${ }^{\dagger}$ Mohnish Pandey, ${ }^{\ddagger}$ and Kristian S. Thygesen ${ }^{\ddagger}$

$\dagger$ Department of Energy Conversion and Storage, Technical University of Denmark, DK-4000 Roskilde, Denmark

$\ddagger$ Department of Physics, Center for Atomic-scale Materials Design, Technical University of Denmark, DK-2800 Kgs. Lyngby, Denmark

E-mail: jmgla@dtu.dk 


\section{Abstract}

The abstract goes here.

\section{Introduction}

High-performance electrochemical storage devices are gaining attention are gaining attention due to the promise of meeting the increasing demand for energy storage for renewable energy sources as well as for electric vehicles. The gravimetric and volumetric energy densities of existing battery technologies are, however, not comparable to that of gasoline, and consequently electric vehicles are not currently a competitive alternative to fossil fuelled cars. ${ }^{1}[\mathrm{FiXme}$ Note: batteries as focus?]

FiXme

An emerging class of $2 \mathrm{D}$ early transition metal materials, the so-called MXenes $\left(\mathrm{M}_{n+1} \mathrm{X}_{n} \mathrm{~T}_{x}\right.$ Note! for $n=1,2,3$, where $\mathrm{M}$ is an early transition metal (e.g. Sc, Ti, V, Hf etc.), X $=\mathrm{C}, \mathrm{N}$ and $\mathrm{T}$ is a functional termination group (typically either $\mathrm{O}, \mathrm{OH}$ or $\mathrm{F}$ ), have been of interest within many fields, including Li-ion batteries. MXenes, are hexagonal layered materials, which are bound by the long range effects, making the description of these dispersion effects of paramount importance when describing properties of stacked MXenes. ${ }^{2+4]}$ [FiXme Note: FiXme I really don't like this phrasing.] The monolayer can be seen in Fig. 1

(a)

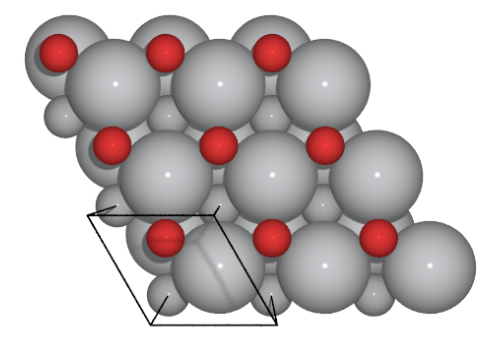

(b)

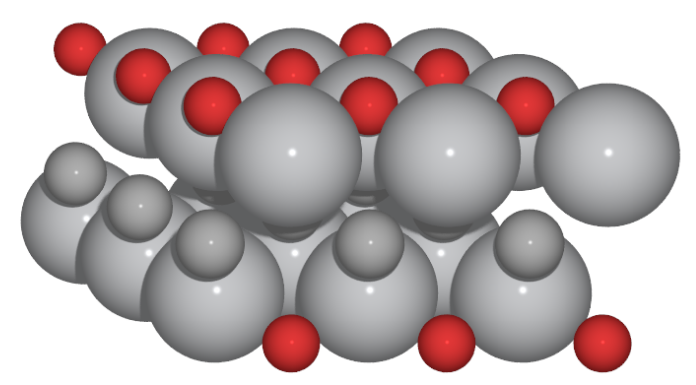

Figure 1: (a) Top view of MXene. (b) Side view.

In Density Functional Theory (DFT), these effects must be accounted for explicitly in the functional, or as a correction, which has been done in several works ${ }^{5} \sqrt{8}$ - however, the 
magnitude of the vdW correction is not unique, and must therefore be tested in the particular system in question. In this work, a selection of long range dispersion functionals will be benchmarked for MXenes, in particular $\mathrm{Ti}_{2} \mathrm{C}$, in order to determine the most appropriate functional. [FiXme Note: Define "appropriate" functional] FiXme

\section{Computational Methods}

The DFT calculations in this work were performed in the Vienna Ab initio Simulation Package (VASP) ${ }^{9}$ along with the Atomic Simulation Environment (ASE) 10 . The projector augmented wave (PAW) ${ }^{11}$ method, combined with pseudopotentials ${ }^{12}$, was used to describe the core electrons. The valence electrons were described by a plane-wave basis set with a $950 \mathrm{eV}$ energy cutoff [FiXme Note: comment on the fairly high cutoff energy?]. The FiXme exchange-correlation (xc) functionals which have been investigated in this work include: the Note! Perdew-Burke-Ernzerhof (PBE) ${ }^{13}$ form of the generalized gradient approximation (GGA) coupled with the D3 $3^{5}$ method for the long range dispersion corrections; the opt-B88-vdW ${ }^{7}$ functional; and finally the vdW-DF2 ${ }^{6}$ functional. [FiXme Note: Add which pseudopo- FiXme tentials? How?]

A smearing of $0.05 \mathrm{eV}$ was applied for the occupation of electronic states, and the calculations were spin-unpolarized. The Brillouin zone was sampled using a $\Gamma$-centered MonkhorstPack $k$-point mesh ${ }^{14}$ - a $9 \times 9 \times 1$ sampling was used to describe the unit cell in of a monolayer and $9 \times 9 \times 9$ for the unit cell of the bulk. [FiXme Note: I guess we should also touch on the size of the k-point mesh in the supercells?] 


\section{Results and Discussion}

\section{References}

(1) Goodenough, J. B.; Park, K.-S. The Li-Ion Rechargeable Battery: A Perspective. J. Am. Chem. Soc. 2013, 135, 1167-1176.

(2) Naguib, M.; Kurtoglu, M.; Presser, V.; Lu, J.; Niu, J.; Heon, M.; Hultman, L.; Gogotsi, Y.; Barsoum, M. W. Two-dimensional Nanocrystals Produced by Exfoliation of $\mathrm{Ti}_{3} \mathrm{AlC}_{2}$. Adv. Mater. 2011, 23, 4248-4253.

(3) Khazaei, M.; Ranjbar, A.; Arai, M.; Sasaki, T.; Yunoki, S. Electronic Properties and Applications of MXenes: A Theoretical Review. J. Mater. Chem. C 2488, 5, 24882503.

(4) Fredrickson, K. D.; Anasori, B.; Seh, Z. W.; Gogotsi, Y.; Vojvodic, A. Effects of Applied Potential and Water Intercalation on the Surface Chemistry of $\mathrm{Ti}_{2} \mathrm{C}$ and $\mathrm{Mo}_{2} \mathrm{C}$ MXenes. J. Phys. Chem. C 2016, 120, 28432-28440.

(5) Grimme, S.; Antony, J.; Ehrlich, S.; Krieg, H. A Consistent and Accurate Ab Initio Parametrization of Density Functional Dispersion Correction (DFT-D) for the 94 Elements H-Pu. J. Chem. Phys. 2010, 132, 154104.

(6) Dion, M.; Rydberg, H.; Schröder, E.; Langreth, D. C.; Lundqvist, B. I. Van der Waals Density Functional for General Geometries. Phys. Rev. Lett. 2004, 92, 246401.

(7) Klimeš, J.; Bowler, D. R.; Michaelides, A. Chemical Accuracy for the van der Waals Density Functional. J. Phys. Condens. Matter 2010, 22, 022201.

(8) Klimeš, J.; Bowler, D. R.; Michaelides, A. Van der Waals Density Functionals Applied to Solids. Phys. Rev. B 2011, 83 . 
(9) Kresse, G.; Furthmüller, J. Efficient Iterative Schemes for Ab Initio Total-energy Calculations Using a Plane-wave Basis Set. Phys. Rev. B 1996, 54, 11169-11186.

(10) Larsen, A.; Mortensen, J.; Blomqvist, J.; Castelli, I.; Christensen, R.; Dulak, M.; Friis, J.; Groves, M.; Hammer, B.; Hargus, C. et al. The Atomic Simulation Environment - A Python Library for Working with Atoms. J. Phys. Condens. Matter 2017, 29, 273002 .

(11) Blöchl, P. E. Projector Augmented-wave Method. Phys. Rev. B 1994, 50, 17953-17979.

(12) Kresse, G.; Joubert, D. From Ultrasoft Pseudopotentials to the Projector Augmentedwave Method. Phys. Rev. B 1999, 59, 1758-1775.

(13) Perdew, J. P.; Burke, K.; Ernzerhof, M. Generalized Gradient Approximation Made Simple. Phys. Rev. Lett. 1996, 77, 3865-3868.

(14) Monkhorst, H. J.; Pack, J. D. Special Points for Brillonin-zone Integrations. Phys. Rev. B 1976, 13, 5188-5192. 